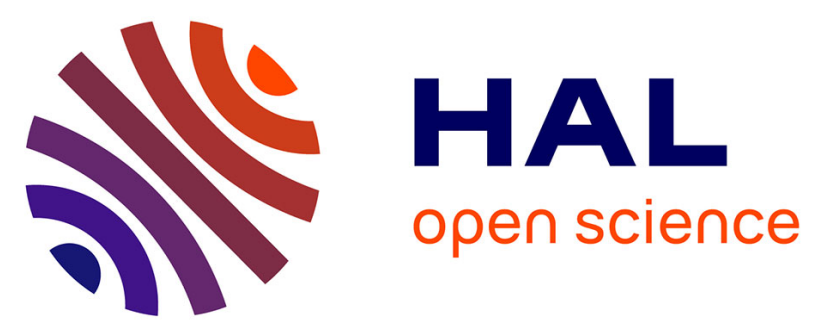

\title{
The CAM-ICU has now a French "official" version. The translation process of the 2014 updated Complete Training Manual of the Confusion Assessment Method for the Intensive Care Unit in French (CAM-ICU.fr)
} Gerald Chanques, Océane Garnier, Julie Carr, Matthieu Conseil, Audrey de Jong, Christine Rowan, E. Wesley Ely, Samir Jaber

\section{To cite this version:}

Gerald Chanques, Océane Garnier, Julie Carr, Matthieu Conseil, Audrey de Jong, et al.. The CAMICU has now a French "official" version. The translation process of the 2014 updated Complete Training Manual of the Confusion Assessment Method for the Intensive Care Unit in French (CAM-ICU.fr). Anaesthesia Critical Care \& Pain Medicine, 2017, 36 (5), pp.297 - 300. 10.1016/j.accpm.2017.02.003 . hal-01767686

\author{
HAL Id: hal-01767686 \\ https://hal.science/hal-01767686
}

Submitted on 16 Dec 2019

HAL is a multi-disciplinary open access archive for the deposit and dissemination of scientific research documents, whether they are published or not. The documents may come from teaching and research institutions in France or abroad, or from public or private research centers.
L'archive ouverte pluridisciplinaire HAL, est destinée au dépôt et à la diffusion de documents scientifiques de niveau recherche, publiés ou non, émanant des établissements d'enseignement et de recherche français ou étrangers, des laboratoires publics ou privés. 


\title{
The CAM-ICU has now a French "official" version. The translation process of the 2014 updated Complete Training Manual of the Confusion Assessment Method for the Intensive Care Unit in French (CAM-ICU.fr)
}

\author{
Gérald Chanques ${ }^{\mathrm{a}, \mathrm{b}, *}$, Océane Garnier ${ }^{\mathrm{a}}$, Julie Carr ${ }^{\mathrm{a}}$, Matthieu Conseil ${ }^{\mathrm{a}}$, Audrey de Jong ${ }^{\mathrm{a}, \mathrm{b}}$, \\ Christine M. Rowan ${ }^{\mathrm{c}}$, E. Wesley Ely ${ }^{\mathrm{c}, \mathrm{d}}$, Samir Jaber ${ }^{\mathrm{a}, \mathrm{b}}$ \\ ${ }^{a}$ Department of anaesthesia and critical care medicine, university of Montpellier Saint-Éloi hospital, Montpellier, France \\ ${ }^{\mathrm{b}}$ PhyMedExp, university of Montpellier, Inserm U1046, CNRS UMR 9214, Montpellier, France \\ ${ }^{\mathrm{C}}$ Department of medicine, division of allergy, pulmonary, and critical care medicine, and the center for health services research, Vanderbilt university school of \\ medicine, Nashville, Tennessee, USA \\ ${ }^{\mathrm{d}}$ Geriatric research education clinical center (GRECC), department of veterans affairs, Tennessee valley healthcare system, Nashville, Tennessee, USA
}

Keywords:

Delirium

Intensive care unit

Critical care

Sedation

\begin{abstract}
A B S T R A C T
Introduction: Delirium is common in Intensive-Care-Unit (ICU) patients but under-recognized by bedside clinicians when not using validated delirium-screening tools. The Confusion-Assessment-Method for the ICU (CAM-ICU) has demonstrated very good psychometric properties, and has been translated into many different languages though not into French. We undertook this opportunity to describe the translation process.

Material and methods: The translation was performed following recommended guidelines. The updated method published in 2014 including introduction letters, worksheet and flowsheet for bed-side use, the method itself, case-scenarios for training and Frequently-Asked-Questions (32 pages) was translated into French language by a neuropsychological researcher who was not familiar with the original method. Then, the whole method was back-translated by a native English-French bilingual speaker. The new English version was compared to the original one by the Vanderbilt University ICU-delirium-team. Discrepancies were discussed between the two teams before final approval of the French version.

Results: The entire process took one year. Among the 3692 words of the back-translated version of the method itself, 18 discrepancies occurred. Eight (44\%) lead to changes in the final version. Details of the translation process are provided.

Conclusions and relevance: The French version of CAM-ICU is now available for French-speaking ICUs. The CAM-ICU is provided with its complete training-manual that was challenging to translate following recommended process. While many such translations have been done for other clinical tools, few have published the details of the process itself. We hope that the availability of such teaching material will now facilitate a large implementation of delirium-screening in French-speaking ICUs.
\end{abstract}

\section{Introduction}

Nearly one third of patients admitted to an Intensive-Care-Unit (ICU) will develop delirium [1]. This is associated with an increased

\footnotetext{
* Corresponding author at: Département d'anesthésie-réanimation (DAR), hôpital Saint-Éloi, centre hospitalier universitaire de Montpellier, 80, avenue Augustin-Fliche, 34295 Montpellier cedex 5, France. Fax: +33 467337448. E-mail address: g-chanques@chu-montpellier.fr (G. Chanques).
}

duration of mechanical ventilation, length of ICU and hospital stays, an increased risk of dying, in hospital or after discharge, as well as of having long term neurocognitive dysfunction [1,2]. Guidelines recommend the routine use of validated clinical tools for the early recognition and treatment of delirium by medical and nurse ICU teams, even if they are non-expert neuropsychologists [3]. The Confusion Assessment Method for the ICU (CAM-ICU) [4] has been extensively studied for more than 15 years, demonstrating good psychometric properties [3]. It has been the screening tool the most 


\section{Discussion}

Delirium is a frequent event in critically ill patients. It is diagnosed in 10 to $90 \%$ of ICU patients depending on the diagnosis tool, the timing of assessment (during light sedation or after interrupting sedation) as well as the frequency of assessment (one point assessment for validation studies or throughout the ICU stay) [3,13]. A recent review of 42 studies found a prevalence of delirium in 5280 of 16,595 (31.8\%) critically ill patients [1]. Although frequent, delirium is under-recognized by ICU teams, both by physicians and nurses. Compared to the CAM-ICU, clinicians' sensitivity to diagnose delirium is close to $30 \%[11,14]$. The original study validating the CAM-ICU reported high sensitivity (from 93\% to 100\%) and specificity (from 98 to $100 \%$ ) [4]. These very good psychometric properties were reported in a very well trained team. It has been shown that the efficiency of a tool like the CAM-ICU as well as pain and sedation scales are highly dependent on the implementation quality process, including education, training and monitoring of the effective implementation in an ICU team [15-18]. To improve the accurate and regular use of the CAM-ICU on a large scale, the 2014 updated method included a complete manual for training with Frequently Ask Questions (FAQ). It is in this way that the Richmond Agitation Sedation Scale (RASS) had previously been translated and validated in French including a teaching annexe and FAQ [16]. We hope that the translation of the entire manual for the CAM-ICU will allow for a larger implementation of this tool in France as it has been the case for the RASS for several years [8,9]. To provide the most accurate tool possible, we followed the recommendations for

Replacement of T.H.I.N.K by T.R.A.I.T.E (meaning TREAT in French),

page 31 of the CAM-ICU method

Yellow highlightment: rephrazing of the American sentence to make it clearer for French

Blue highlightment: new item added to THINK, that has already been included in our former list of important causes to look for while "thinking" about delirium

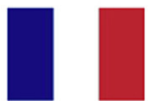

\section{T.R.A.I.T.E la confusion mentale}

La reconnaissance de la confusion mentale est comme une alarme anti-intrusion. Elle nous force à considérer les causes identifiables et traitables au plus tôt, en évitant les mauvais réflexes (traitement d'une agitation par neuroleptique sans traitement de la cause = mauvais réflexe).

Toxiques : médicaments et toxiques (exposition ou sevrage), défaillance viscérale (foie, rein)

Respiration : Hypoxémie, Hypoxie tissulaire (insuffisance cardiaque congestive, choc), Hypercapnie

Alternatives thérapeutiques non médicamenteuses : mobilisation et exercice précoces, prothèses auditives, aides visuelles (lunettes), réorientation, hygiène du sommeil, musicothérapie, contrôle du bruit

Infection/sepsis, Inflammation, ou existe-il une nouvelle Infection nosocomiale ?, Immobilisation

Trouble hydro-électrolytique, métabolique ou hormonal

Epilepsie infra-clinique et autre pathologie de l'encéphale (accident vasculaire)

\section{Back-translation}

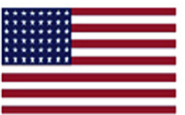

Delirium recognition is like a burglar alarm for us. It forces us to consider identifiable, treatable causes earlier, and prevents bad knee-jerk reactions (treating an agitation with neuroleptics without any research of its cause $=$ bad knee-jerk reaction)

Toxics: medications and toxics (exposition or withdrawal), organ failure (liver, kidney)

Respiration: Hypoxemia, tissue Hypoxia (congestive heart failure, shock), Hypercabnia

Alternative non-pharmacological therapeutics: early mobilization and exercizes,

hearing aids, visual aids (glasses), reorientation, sleep hygiene, music-therapy, noise control

Infection/sepsis, Inflammation, ou is there a new nosocomial Infection? Immobilization

T for Trouble (disorder, problem) : electrolyte, metabolic or hormonal problem

Epilepsy infra-clinical and other encephale's disease (stroke)

Fig. 2. Translation process of the bundle acronym for the treatment of delirium causes through a collaborative approach between the French and the American teams. 
